\title{
RELATIONSHIP BETWEEN INVOLVEMENT IN LONG- TERM REGULAR PHYSICAL ACTIVITY AND MEMORY: PRELIMINARY RESULTS
}

\author{
Kristine Sneidere, Jelena Harlamova, Zane Ulmane, \\ Voldemars Arnis, Andra Vanaga, Ainars Stepens \\ Riga Stradiņš University, Riga, Latvia
}

\begin{abstract}
Background. Ageing of the Western Society has become both - economic and social concern. Ageing has both - biological and psychological consequences, and, with changes in the brain due to ageing (e.g. decline in the brain volume in frontal, parietal and temporal areas, as well as hippocampus (Colcombe et al., 2003; Erickson, Voss, Shaurya, Basak, \& Szabo, 2011)), there are changes in cognitive functioning. For the past years, research has indicated a relationship between aerobic activity interventions and increase in episodic memory (Ruscheweyh et al., 2011), face recognition associative memory (Hayes et al., 2015) and working memory (Erickson et al., 2011).

Methods. The aim of the study was to examine the relationship between involvement in aerobic physical activities and memory; thus 43 seniors aged from 65 to 85 ( $M=71.86, S D=5.09,23 \%$ male) were included in the study. Based on their physical activity experience, participants were divided into three groups - seniors with longterm aerobic physical activity experience $(n=16)$, seniors that have recently taken up aerobic physical activities $(n=19)$ and seniors not involved in physical activities $(n=8)$.

Results. The preliminary data indicated relationship between long-term involvement in physical activities and working memory, as well as negative relationship between sedentary lifestyle and overall cognitive abilities.

Conclusions. As this is still a work in progress, one of the limitations being the small sample, these results can be considered only as a tendency. Another limitation is the unequal gender distribution. This study was funded by the Latvian National Research Programme BIOMEDICINE 2014-2017.
\end{abstract} memory.

Keywords: aerobic physical activity, associative memory, long-term memory, short-term memory, working

\section{INTRODUCTION}

U $\mathrm{p}$ until the second half of the $20^{\text {th }}$ century the research on the impact of aerobic physical activities was focused mostly on its relationship with cardiovascular health; however, in the year 1975 a study connecting physical activity with the reaction and movement time was conducted (Spirduso, 1975). This research suggest that aerobic physical activities are not only beneficial for cardiovascular health, but also for the cognitive functioning. For the past decade, research on the impact of physical activity has grown, considering not only the increase in the prevalence of chronic diseases in the population, but also the rapid aging of the Western society (World Health Organization, 2015). While aging is an inevitable part of a life cycle, it impacts not only the physical body, but the mind as well. It has been estimated that with the age of 30 , the human brain starts losing its volume and, in the time span from 30 to 90 years, approximately $15 \%$ of the cortex and $25 \%$ of the white matter is lost (Colcombe et al., 2003). Substantially, loss of the grey and white matter leads to a decline in cognitive functioning.

It has been found that aging does in fact impact working memory (Boucard et al., 2012; Voss et al., 2013), while having very little effect on implicit memory (Goh \& Park, 2009). With aging, it becomes harder to encode new information in both - episodic and semantic memory, while the existing autobiographic and semantic memories 
can stay relatively stable (Hedden \& Gabrieli, 2004), another research indicates decline in episodic memory which is explained as a decline in the ability to create associations between the object and the situation (associative memory) (ReuterLorenz \& Park, 2010). For the past years, physical activity, especially aerobic physical activity, has been considered a major contributor to brain neuroplasticity, helping to overcome to cognitive decline due to ageing (Pin-Barre \& Laurin, 2015). Research indicates such positive influence of aerobic activities to cognitive processes, as improved working memory (Voss et al., 2010), improved episodic memory performance (Ruscheweyh et al., 2011), improvement of face-name relational memory and visual memory (Hayes et al., 2015).

So far there has been a very little research on the impact of long-term aerobic physical activities on memory and the results have been controversial. A study by Young (2016) was conducted on 50 participants who were then divided into two groups based on their life style habits - professional athletes and socially active seniors. The results of the study indicated changes in brain structure, however, not in memory measures. Taking into consideration the positive results from short term intervention studies, the aim of the present study was to examine the impact of long-term aerobic physical activities on memory in seniors with different physical activity experience.

\section{METHODS}

Participants. Forty-three seniors aged from 65 to $85(M=71.86, S D=5.09,23 \%$ male) participated in the study. For data analysis, participants were divided into three groups based on their aerobic physical activity experience. In the first group there were seniors with long-term regular aerobic physical activity experience, who also were involved into competitive sports $(n=16)$, in the second group - seniors who recently were involved in regular aerobic physical activities were included $(n=19)$, in the third group - participants with overall sedentary life style $(n=9)$. Mean years of education of the participants were 15.53 years $(S D=3.97)$ (see Table 1).

All participants were native Latvian speakers with no known medical history of cardio-vascular, metabolic disorders, pulmonary and respiratory diseases that require medication, ongoing oncological diseases, rheumatologic diseases that require pain medication or mental diseases.
Table 1. Participant Characteristics

\begin{tabular}{|l|c|c|c|}
\hline Characteristics & Mean & Range & SD \\
\hline Age & 71.86 & $65-85$ & 5.09 \\
\hline Education (y) & 15.53 & $7-25$ & 3.97 \\
\hline
\end{tabular}

Note. $S D$ - Standard Deviation.

Instruments. For overall screening, Montreal Cognitive Assessment Scale ( $M o C A$; Nasreddine et al., 2005) was used. This test consists of twelve tasks, assessing visual-spatial perception, executive functions, short and long term memory as well as working memory, attention, thinking processes, language skills and orientation in time and place. The maximal count of points was 30 , the accepted norm was 26 points.

To assess working memory, The Numbers Reversed subtest (Woodcock-Johnson Test of Cognitive Abilities, Woodcock, McGrew, \& Mather, 2001) was used. In this test, participants were presented with a series of digits which had to be repeated in reverse order.

The associative memory was assessed with The Memory for names subtest (Woodcock-Johnson Test of Cognitive Abilities, Woodcock, McGrew, \& Mather, 2001), which is used to assess not only associative memory, but also the retrieval from the longterm memory. Participants were presented with pictures of aliens and given their names and they had to recognise the picture and the name of each alien.

The short-term and the long-term memory, as well as the dynamics of memory processes, were assessed by using Memory Ten-word test (Luria, 1976). In this test, participants were presented with ten one or two syllable words, which participants had to listen and then repeat five times in a row and then one time after 45 minutes.

To identify the overall tendencies in each of the participant's lifestyle, a modified version of Social Determinants of Health Behaviours questionnaire (FINBALT, 2008) was used. This questionnaire includes questions regarding their physical activity over their course of life (e.g. What kind of aerobic exercises have you been involved during your life?), the regularity of the exercises and activities for the past years, months and weeks. The questionnaire also includes questions that reflects participants' habits of alcohol use, smoking, and diet.

Procedure. Data collection for each participant lasted in two stages (two days). On the first day, the assessment of executive functioning was conducted, on the second day, the data on each participant's lifestyle was obtained. Ethical approval 
has been obtained from the Riga Stradiņš University Ethics Committee. Participation was voluntary and written consent was obtained from each of the participants prior to data collection.

Data analysis. SPSS version 21 (Statistical Package for the Social Sciences) was used to process the data. The data was analysed applying Pearson's correlation coefficient and ANOVA analysis with Post Hoc test (Scheffe).

\section{RESULTS}

The mean results of the tests assessing memory and overall screening were calculated. Group with the long term aerobic experience showed higher working-memory and associative memory results, while short and long-term memory test results were higher in the short term aerobic physical activity group. MoCA screening test results were similar in both physically active groups. Results for sedentary groups were lower in all memory measures (See Table 2).
To determine, whether there were significant differences across the three groups, analysis of variance (ANOVA) with Scheffe Post Hoc correction was used. However, there were no significant differences between the groups $(p>.05)$. Effect size in associative memory, working memory, short-term memory and MoCA test were low.

To determine whether there was a relationship between involvement in physical activities and working memory, associative memory, short and long-term memories and cognitive screening, Pearson's correlation coefficient was used.

Correlation analysis indicated statistically significant positive correlation between longterm involvement in physical activities and working memory $(r=.34, p<.05)$ and statistically significant, but negative correlation between sedentary group and MoCA test results $(r=-.32$, $p<.05$ ). There were no statistically significant correlations between the groups' that were recently involved in physical activities memory and overall cognitive measures (see Table 3 ).

Table 2. Descriptive characteristics and inferential statistics of the results from memory tests and MoCA test

\begin{tabular}{|c|c|c|c|c|c|c|c|c|}
\hline & \multicolumn{8}{|c|}{ Time and regularity of the physical activity } \\
\hline & \multicolumn{2}{|c|}{$\begin{array}{l}\text { Long-term group } \\
\qquad(n=16)\end{array}$} & \multicolumn{2}{|c|}{$\begin{array}{l}\text { Recent group } \\
\quad(n=19)\end{array}$} & \multicolumn{2}{|c|}{$\begin{array}{l}\text { Sedentary group } \\
\qquad(n=8)\end{array}$} & \multirow[t]{2}{*}{$\boldsymbol{F}$} & \multirow[t]{2}{*}{$\eta^{2}$} \\
\hline & $M$ & $S D$ & $M$ & $S D$ & $M$ & $S D$ & & \\
\hline Memory of names & $113.94_{\mathrm{a}}$ & 9.07 & $108.16_{\mathrm{a}}$ & 7.57 & $105.75_{\mathrm{a}}$ & 9.95 & 1,59 & .074 \\
\hline Numbers reversed & $107.36_{a}$ & 12.53 & $95.52_{\mathrm{a}}$ & 20.73 & $94.52_{\mathrm{a}}$ & 10.74 & 2.67 & .118 \\
\hline Short-term memory & $5.69_{\mathrm{a}}$ & 1.20 & $6.21_{\mathrm{a}}$ & 1.65 & $5.37 \mathrm{a}$ & 1.30 & .20 & .054 \\
\hline Long-term memory & $6.94_{a}$ & 2.67 & $7.05_{\mathrm{a}}$ & 2.34 & $5.88_{\mathrm{a}}$ & 2.30 & 1.58 & .001 \\
\hline MoCA test & $25.43_{\mathrm{a}}$ & 2.22 & $25_{\mathrm{a}}$ & 2.56 & $23_{\mathrm{a}}$ & 3.34 & 2.46 & .109 \\
\hline
\end{tabular}

Note. $N=43$. Long-term group - seniors with long-term regular aerobic physical activity experience, who were also involved into competitive sports, recent group - seniors, who recently started doing regular physical activities, sedentary group - seniors who were not involved in regular physical activities. In each line the means that have a common letter in subscript do not statistically differ $(p>.05)$. $\eta^{2-}$ effect size.

Table 3. Relationship between involvement in physical activities, memory measures and overall cognitive screening measures

\begin{tabular}{|l|c|c|c|c|c|c|c|c|}
\hline & $\mathbf{1 .}$ & $\mathbf{2 .}$ & $\mathbf{3 .}$ & $\mathbf{4 .}$ & $\mathbf{5 .}$ & $\mathbf{6 .}$ & $\mathbf{7 .}$ & $\mathbf{8 .}$ \\
\hline 1. Long-term group & - & & & & & & & \\
\hline 2. Recent group & $-.66^{* *}$ & - & & & & & & \\
\hline 3. Sedentary group & $-.37^{*}$ & $-.41^{* *}$ & - & & & & & \\
\hline 4. Memory of names & .25 & -.15 & -.19 & - & & & & \\
\hline 5. Numbers reversed & $.34^{*}$ & -.22 & -.15 & .12 & - & & & \\
\hline 6. Short-term memory & -.09 & .20 & -.16 & .20 & .03 & - & & \\
\hline 7. Long-term memory & -.01 & .01 & -.02 & .17 & .21 & $.56^{* *}$ & - & \\
\hline 8. MoCA test & .19 & .10 & $-.32^{*}$ & .33 & $.41^{* *}$ & .22 & -.16 & - \\
\hline
\end{tabular}

Note. $N=43$. Long-term group - seniors with long-term regular aerobic physical activity experience, who were also involved into competitive sports, recent group - seniors, who recently started doing regular physical activities, sedentary group - seniors who were not involved in regular physical activities. * indicates statistically significant correlation $(p<.05)$. 


\section{DISCUSSION}

The aim of this study was to examine the impact of long-term aerobic physical activities on memory. The amount of research on the impact of physical activity on cognitive functions is growing, now taking into consideration not only aerobic activity as the most suitable type of physical exercise for improvement or maintenance of cognitive function, but more and more taking into consideration strength training. Research also such encompassed such exercises as balance training that has been indicated to improve memory and spatial cognition (Rogge et al., 2017).

In the present study, we found no significant differences regarding the activity, the length of the activity; however, the mean results in all cognitive process measures were higher for the physically active groups, which complies with previous research on physical activity and its relationship with cognitive functions (e.g. Middleton, Barnes, Lui, \& Yaffe, 2010). Relationship between the involvement in physical activity and memory measures were found only between long-term physical activity involvement and working memory measures. Research indicates that indeed involvement in aerobic physical activities can be beneficial in improving working memory (e.g. Voss et al., 2013). This might relate to the increase in grey matter volume in frontoparietal circuity, which is associated with working memory (Karlsgodt,
2015), and has been shown to increase after aerobic physical activity interventions (Erickson, Voss, Shaurya, Basak, \& Szabo, 2011). There was negative relationship between sedentary lifestyle and overall cognitive assessment, which indicates that either short- or long-term involvement might be beneficial also for the overall cognitive processes.

As this is still a work in progress, the results should be considered only as possible tendencies, as the data analysis has so far been conducted on a very small sample, this being one of the main limitations. Another limitation is the lack of strong criteria for measuring retrospective physical activity, as the physical activity of participants vary across the physical exercise as well as other physical activities.

\section{CONCLUSION}

The results of the study indicate that longer involvement in physical activities might be more beneficial for working memory than short-term involvement or sedentary lifestyle; however, due to limitation and this being a work in progress, further research is still necessary to draw stronger conclusions. For future research it would be beneficial to develop means of measuring physical activity in retrospect.

Acknowledgements. This study is conducted under the State Research Programme BIOMEDICINE, sub-project No. 5.8.2.

\section{REFERENCES}

Bherer, L., Erickson, K. I., \& Liu-Ambrose, T. (2013). A review of the effects of physical activity and exercise on cognitive and brain functions in older adults. Journal of Aging Research. doi: http://dx.doi.org/ 10.1155/ 2013/657508.

Boucard, G. K., Albinet, C. T., Bugaiska, A., Bouquet, C. A., Clarys, D., \& Audiffren, M. (2012). Impact of physical activity on executive functions in aging: A selective effect on inhibition among old adults. Journal of Sport and Exercise Psychology, 34, 808-827.

Colcombe, S. J., Erickson, K. I., Raz, N., Webb, A. G., Cohen, N. J., Mcauley, E., \& Kramer, A. F. (2003). Aerobic fitness reduces brain tissue loss in aging humans. Journal of Gerontology, 58(2), 176-180.

Erickson, K. I., Voss, M. W., Shaurya, R., Basak, C., $\&$ Szabo, A. (2011). Exercise training increases size of hippocampus and improves memory. Proceedings of the National Academy of Sciences of the United States of America, 108(7), 3017-3022. http://doi.org/10.1073/ pnas. 1015950108
FINBALT. (2008). Heath Behaviour among Latvian Adult Population, 2008. Retrieved from https://www. spkc.gov.lv/upload/Petijumi un zinojumi/FINBALT/ finbalt_2008_i_ii_iii_dala.pdf

Goh, J. O., \& Park, D. C. (2009). Neuroplasticity and cognitive aging: the scaffolding theory of aging and cognition. Restorative Neurology and Neuroscience, 27(5), 391-403. http://doi.org/10.3233/RNN-2009-0493 Hayes, S. M., Alosco, M. L., Hayes, J. P., Cadden, M., Peterson, K. M., Allsup, K., ... Verfaellie, M. (2015). Physical activity is positively associated with episodic memory in aging. Journal of the International Neuropsychological Society, 21(10), 780-790. http:// doi.org/10.1017/S1355617715000910

Hedden, T., \& Gabrieli, J. D. E. (2004). Insights into the ageing mind: A view from cognitive neuroscience. Nature Reviews Neuroscience, 5(2), 87-96. http://doi. org/10.1038/nrn1323

Hurtig-Wennlöf, A., Hagströmer, M., \& Olsson, L. A. (2010). The International Physical Activity Questionnaire 
modified for the elderly: Aspects of validity and feasibility. Public Health Nutrition, 13(11), 1847-1854. http://doi.org/10.1017/S1368980010000157

Karlsgodt, K. H. (2015). Working Memory. In Brain Mapping: An Encyclopaedic Reference Vol. 3. (pp. 319-326). Elsevier Inc. http://doi.org/10.1016/ B978-0-12-397025-1.00249-9

Luria, A. (1976). The neuropsychology of memory. New York: John Wiley Press.

Middleton, L. E., Barnes, D. E., Lui, L., \& Yaffe, K. (2010). Cognitive performance and impairment in old age. Journal of the American Geriatrics Society, 58, 1322-1326. http://doi.org/10.1111/j.1532-5415.2010.02903.x

Pin-Barre, C., \& Laurin, J. (2015). Physical exercise as a diagnostic, rehabilitation, and preventive tool: Influence on neuroplasticity and motor recovery after stroke. Neural Plasticity, 1-12.

Reuter-Lorenz, P. A., \& Park, D. C. (2010). Human neuroscience and the aging mind: A new look at old problems. The Journals of Gerontology. Series B, Psychological Sciences and Social Sciences, 65(4), 405-415. http://doi.org/10.1093/geronb/gbq035

Rogge, A.-K., Röder, B., Zech, A., Nagel, V., Hollander, K., Braumann, K.-M., \& Hötting, K. (2017). Balance training improves memory and spatial cognition in healthy adults. Scientific Reports, 7, 5661. http://doi. org/10.1038/s41598-017-06071-9
Ruscheweyh, R., Willemer, C., Krüger, K., Duning, T., Warnecke, T., Sommer, J., ... Flöel, A. (2011). Physical activity and memory functions: An interventional study. Neurobiology of Aging, 32(7), 1304-1319. http://doi. org/10.1016/j.neurobiolaging.2009.08.001

Spirduso, W. W. (1975). Reaction and movement time as a function of age and physical activity level. Journal of Gerontology, 30(4), 435-40. Retrieved from http:// www.ncbi.nlm.nih.gov/pubmed/1141674

Voss, M. W., Heo, S., Prakash, R. S., Erickson, K. I., Alves, H., Chaddock, L., ... Kramer, A. F. (2013). The influence of aerobic fitness on cerebral white matter integrity and cognitive function in older adults: Results of a one-year exercise intervention. Human Brain Mapping, 2985, 2972-2985. http://doi.org/10.1002/ hbm.22119

Young, J. C., Dowell, N. G., Watt, P. W., Tabet, N., \& Rusted, J. M. (2016). Long-term high-effort endurance exercise in older adults: Diminishing returns for cognitive and brain aging. Journal of Aging and Physical Activity, 24(4), 659-675.

Woodcock, R. W., McGrew, K. S., Mather, N. (2001). Woodcock-Johnson III Test Manual (III). Itasca, IL: Riverside Publishing Company.

World Health Organization. (2015). World report on ageing and health. Retrieved from www.who.int/ 